\title{
Multiple fibroadenoma of the breast
}

INSERM

\section{Source}

INSERM. (1999). Orphanet: an online rare disease and orphan drug data base. Multiple fibroadenoma of the breast. ORPHA:50920

Mammary polyadenomatosis is characterised by the presence in both breasts of multiple voluminous fibroadenomas with heterogeneous echo patterns. 